\title{
Social Media Surveillance in Social Work: Practice Realities and Ethical Implications
}

\author{
Julie Byrne, Gloria Kirwan \& Conor Mc Guckin
}

To cite this article: Julie Byrne, Gloria Kirwan \& Conor Mc Guckin (2019): Social Media Surveillance in Social Work: Practice Realities and Ethical Implications, Journal of Technology in Human Services, DOI: 10.1080/15228835.2019.1584598

To link to this article: https://doi.org/10.1080/15228835.2019.1584598

$$
\text { 曲 Published online: } 04 \text { Apr } 2019 .
$$

Submit your article to this journal

Цll Article views: 169

View Crossmark data $\nearrow$ 


\title{
Social Media Surveillance in Social Work: Practice Realities and Ethical Implications
}

\author{
Julie Byrne (D), Gloria Kirwan (D) and Conor Mc Guckin (D) \\ Trinity College Dublin, Dublin, Ireland
}

\begin{abstract}
This article reports on findings from a study with recently qualified social workers on the use of social media in their practice. The findings reported here are drawn from a broader study on the use of electronic communications conducted with both newly qualified teachers and social workers. The focus group data reported here provide an insight into the practice realities associated with the use of social media by clients and social workers. The qualitative methodology employed helps to reveal the richness and complexity of technology use in practice. This rich picture reveals multidirectional surveillance, by clients and social workers, facilitated by social media. This includes surveillance by clients taking videos of meetings without consent. The article also highlights situations when social workers themselves consider it acceptable to gather information on clients through social media. The research identifies a range of ethical issues for social workers to navigate and highlights their need for support and guidance in the form of standards, codes, and education and training. The surveillance lens illuminates the ethical dilemmas being faced with reference to concepts such as power, privacy and consent as well as the broader debate of care and control in social work.
\end{abstract}

\section{ARTICLE HISTORY}

Received 26 July 2018

Accepted 12 February 2019

\section{KEYWORDS}

Confidentiality and privacy of information; electronic monitoring; impact of technology; networked society

\section{Introduction}

In 2013, prompted by media reports of misconduct cases regarding the use of electronic communications across a range of disciplines, a small research project was initiated by colleagues in Trinity College Dublin, Ireland, drawing on expertise from the School of Social Work and Social Policy and the School of Education. The project initially set out to collect the views of recently graduated social workers and teachers to ascertain their views on the ethical dimensions of the use of electronic communications. Findings from the first phase of data collection related to this study have been previously reported (Kirwan \& Mc Guckin, 2014). Growing awareness regarding the rapid pace of developments in the field of technology in general, and electronic communication in particular, caused the research team to reflect 
on the need to update this study. This reflection prompted a second round of data collection in 2017 to 2018 and it is in this second round of data collection that the issue of surveillance first emerged as a prominent theme in the focus group interviews. Reviewing the first round of interviews, the theme of surveillance was also identified but had not been discussed in the level of detail which the second round of interviews produced and had not been foregrounded in the key findings at that point. It is difficult to ascertain if surveillance was a theme to which the research team did not give sufficient attention during the analysis of the first set of interviews or if it has become a more prevalent issue for practitioners. Nonetheless, the more recent phase of data collection has revealed the issue of surveillance as a topic on which newly graduated social workers have a lot to say based on relevant practice experience of the issue.

This article focuses specifically on the ways in which social media technologies facilitate contact and surveillance among multiple parties in social work services and on the real and serious ethical dilemmas this poses for newly qualified and experienced practitioners alike. A particular focus of this article is how newly qualified social workers frame the use of social media with clients within a surveillance paradigm. The article explores how the study participants differentiate between the types of contact or information gathering on social media which they classify as appropriate or potentially helpful, and those that they regard as intrusive or coercive as they transgress boundaries between client and professional.

This article returns to look in deeper detail at these debates refreshed with up-to-date information from the focus group interviews on current practice realities. The analysis revealed that for some participants, managing risk assessments could justify the search for electronically held information on service users, be that on the client's Facebook page or other social media platforms. For other participants, using new technologies as surveillance or investigative tools was an unacceptable breach of service users' personal privacy. A new aspect of surveillance highlighted by participants is the use of social media by clients to conduct surveillance on social workers as well as on family members.

The contribution of this study is its focus on newly qualified social workers and its qualitative methodology which helps to reveal the richness and complexity of technology use in practice. This rich picture reveals a world of multi-directional surveillance facilitated by social media use. In common with other studies (Breyette \& Hill, 2015; Mishna, Bogo, Root, Sawyer \& Khoury-Kassabri, 2012), this study identifies a range of ethical issues for the social work professional to unravel. The surveillance lens illuminates how these ethical dilemmas intersect with concepts such as power, privacy and consent as well as the broader debate of care and control in social 
work. The social workers' needs for education and training on these issues as well as practical support are highlighted.

\section{Literature review}

There has been a well-rehearsed debate within the field of social work for many decades regarding the extent to which the practice of social work should be about care or control. A full review of the literature on this issue is beyond the scope of this article but the essential tension it reveals is the self-positioning of social work as a profession which espouses a social justice outlook (Fook, 2016) while at the same time, in many countries, some of its work on behalf of the state is concerned with the identification and management of risk-related behavior.

The intrinsic power dimensions attaching to the work of social workers has prompted calls from writers such as Heron (2005) for social workers to be alert to the power relations which surround their practice. Generally, calls in the literature for deep-level self-reflection (Kondrat, 1999) and a commitment to anti-oppressive practice (Dominelli, 2002) have focused on the practice of social work in the context of direct face-to-face engagement with people who use social work services. The mainstream social work literature has offered less guidance and discussion on the features of such approaches in online interactions or, what principles of practice should be to the forefront in guiding practice which incorporates networked communication technologies. Indeed, the literature is sparse in its consideration of the potential for oppression of clients by social workers, or indeed oppression of social workers, in online or digital contexts.

The challenges and opportunities that networked technologies bring to social services users and practitioners has long been recognized in some specialized fora. Parton (2006) suggests that new technologies require social workers and social service providers to engage with a new terrain of knowledge, one which is less focused on the "social" dimension of their work and more focused on the "informational" domains of practice. Similarly, the connections between a networked society (LaMendola, 1988) and a surveillance society have been previously charted by authors such as Nellis (2010) who points out that technology fundamentally alters the relational aspects of relationship work. In a special issue of this journal on "Human Services in a Networked Society," Ballantyne and LaMendola (2010) highlight the dynamic context and impacts of networked communication technologies on human services grounded as they are in human communication and relationships. The more we use technology, the more we see that its use cannot be left to market and political forces but rather, must be placed firmly within 
"the arena of public concern and debate" (Glastonbury \& LaMendola, 1992, p. 14).

The findings reported in this article shed light on the types of interactions using networked communication technologies which newly qualified social workers are encountering in practice and which, it is suggested, need to be theorized and incorporated into discussions within the care/control debate.

Marwick (2012) draws our attention to underlying dynamics of power and control which can surround the collection of information about individuals - in any context. She examines the phenomenon of social surveillance, where individuals access information posted publicly on social media in a focused manner and without the subject's knowledge. This highlights the scope for the power asymmetry which characterizes many professional/ client relations to be amplified through use of social media. The professional accesses a client's information on social media; however, the client cannot access similar information on the professional. This power asymmetry is of particular relevance to social work given the profession's commitment to social justice. Although specialized journals, such as the Journal of Technology in Human Services, have promoted scholarship on the topic, the literature dealing with online surveillance in social work is sparse in mainstream practice journals. The issue of online surveillance in social work can be located within a broader push for increased respect for personal privacy within electronic media, a push which is driven by awareness of the increasingly ubiquitous and boundaryless nature of such forms of communication and the realization that privacy invasion is not simply a technical issue but has real-life psychological consequences for people who experience it (Yao, Rice \& Wallis, 2007).

When this debate is examined within the realm of professional/client relations, a number of tensions emerge. On the positive side, Ventola (2014) identifies a number of benefits including enhanced patient care and education for health professionals using social media. LaMendola (2010) explores how social media can increase the social presence necessary for relationship-based social work, while Simpson (2017) demonstrates how electronic communication facilitates a "new" social work practice. There is also emerging evidence that social media usage by certain groups within society is spawning new forms of behavior requiring new forms of responses from service providers. There are a number of positive examples of networking and online support now available to people who may have experienced intense isolation or lack of peer connectivity before the advances in modern technology. However, there are also examples of negative behaviors or uses of technology which pose challenges for services engaged in trying to combat gang violence (Patton, Eschmann, Elsaesser, \& Bocanegra, 2016), human trafficking (Yonkova \& Kirwan, 2018), and 
child pornography (Jewkes \& Andrews, 2005). The literature is playing catch-up with the many emerging ways that services need to keep apace of online activity, and this article aims to shed light on the findings from one small study which have illuminated the issue of surveillance in social work practice.

The distinctive nature of electronic communication is part of the landscape which practitioners need to appreciate. The level of penetration of social media into the lives of anyone who has access to digital devices is exponential (Bekkers, Edwards \& de Kool, 2013). In this context, Judd and Johnston (2012) highlight the easy spread of information through social media, which can be both purposeful and inadvertent. Furthermore, Mishna and colleagues (2012) discuss a range of ethical and boundary concerns potentially arising from the use of electronic communications in social work practice. Breyette and Hill (2015) identify the potential to erode trust in the client/social worker relationship through unacceptable use of electronic communications where clients may perceive a lack of diligence or competence on the part of social workers and thus they may feel less trusting of their social worker's commitment or ability to uphold confidentiality and privacy guidelines.

The ethics of monitoring the public's social media content has been highlighted as a somewhat contentious field (Bekkers et al., 2013). Arguments in favor of public agencies monitoring online communications rest on the potential for awareness of trends on social media to act as an aid to responsive "government." Arguments against online monitoring argue that individuals must be at liberty to engage in online activities free of any Big Brother-type oversight of their online behavior by organs of the state. The importance of transparency and respect for privacy are highlighted by Bekkers and colleagues (2013) as some of the ethical issues which monitoring of any type must address. The type of surveillance discussed by participants in the present study is more small scale than anything contemplated by Bekkers and colleagues (2013). Indeed, most of the examples provided by this study's participants involved one client or one family and were not the type of public monitoring exercises which Bekkers and colleagues envisaged. At the same time, the monitoring discussed by the present study's participants covers issues which were typically of a highly personal nature.

\section{Ethical dilemmas}

Before proceeding to report the set of findings on surveillance which the present study has produced, it is useful to reflect briefly on a number of points related to the ethical use of digital technologies in social work. The use of electronic communications in general, which includes social media 
use, has led to an ethical gray space (Kirwan, 2012; Mishna et al., 2012), mainly because, it is suggested here, the relevant bodies, such as professional associations, licensing agencies, and regulators have not managed, so far, to review ethical guidelines at the same pace as new issues emerge in electronic communications.

In Ireland, practicing social workers are required to register with the Social Workers Registration Board and must adhere to the Board's published Code of Professional Conduct and Ethics (CORU, 2011, 2019). The newly published Code (February 2019) contains direction in a number of areas that may relate to the use of technology in practice. These areas include communication, privacy, confidentiality, seeking informed consent and a new section on the use of social media. Section 4 of the new Code (CORU, 2011, p. 19, 2019, p. 11) outlines the conduct requirements in relation to the use of social media:

1. You must:

(a) use social media in a responsible way adopting the same professional standards expected in other forms of communication with service users and others.

(b) always consider the possible impact on service users and others before publishing any material, information or comments on social media, taking care to avoid abusive, unsustainable or defamatory comments.

2. You must not:

(a) use social media in a way that would breach any of your obligations under this Code.

(b) discuss or comment on service users on social media platforms.

3. You should:

(a) use appropriate privacy settings in your use of social media and consider how information and images you post might be interpreted by service users and others were they to become widely available.

(b) maintain professional boundaries in the use of social media to preserve public trust and confidence in your profession.

In fact, the more principle based direction in the Code under the heading "Upholding human rights in your practice" may be a more useful navigation tool for professionals dealing with the surveillance issues described in this article:

You should uphold human rights in your practice, by (CORU, 2011, p. 5):

- respecting the right to self-determination,

- promoting the right to participation, and

- treating each person in a caring and respectful fashion. 
This revised Code of Professional Conduct and Ethics contains more guidance on was recently issued by the Irish Social Workers Registration Board for public consultation and is likely to be published in 2019 to replace the 2011 Code. However, even this updated document does not match the level of detail seen in technology specific guidelines such as the Standards for Technology in Social Work Practice (NASW, ASWB, CSWE \& CSWA, 2017) issued by the National Association of Social Workers (NASW), Association of Social Work Boards (ASWB), Council on Social Work Education (CSWE) and Clinical Social Work Association (CSWA). This lengthy and comprehensive document, grounded in research, was the result of collaboration across four organizations. It provides guidance for social workers on the use of technology in the design and delivery of services as well as the gathering, managing, and storing of information gathered electronically.

In the absence of detailed guidelines or ethical codes, practitioners may rely on recent literature as a guide to best practice. An example of such literature is Barsky (2017), who highlights the many contextual factors which need to be taken into account in determining ethical appropriateness in technology use in social work. For example, there is no clear consensus on whether it is justified to search for clients online if the client's profile is public (Gabbard, Kassaw \& Perez-Garcia, 2011). In Breyette and Hill's study (2015), for example, some social workers had an ethical problem searching for client information on social media, whereas others perceive no such problem if this information is publicly available. The use of social media as a route to gathering information on a client can be seen as unacceptable in general contexts but acceptable where the search is designed to assess their safety (Breyette \& Hill, 2015). Within the realm of child protection, the use of fake social media accounts in order to become online friends with clients to gather information may be a practice reality (Breyette \& Hill, 2015), but it is not without its ethical implications and is, therefore, a contentious practice within the profession. In summary, the acceptability or not, among social workers of importing a range of social media behaviors into their practice is hard to determine at the present level of knowledge on this issue. This leads Breyette and Hill (2015) to highlight the importance of incorporating guidelines into professional curricula and agency policies. It is hoped that the findings of our small-scale study will contribute to building the necessary knowledge which the profession requires.

Gabbard and colleagues (2011) point out that even without specific ethical codes on social media use, professionals should be aware that their use of blogs or social networking sites has the scope to breach standards of professionalism if, for example, one talks about patients disparagingly. Reamer (2017) identifies a range of ethical issues arising from the use of digital technologies in social work including privacy and confidentiality, 
boundaries, dual relationships, and conflicts of interest and practitioner competence. He highlights the need for nuance in assessing the ethical implications of technology use. Some digital technologies, for example, encrypted exchange of documents on e-mail, may offer clients more robust guarantees of confidentiality than the exchange of paper records via the traditional postal system. However, other technologies such as social media, offer the potential for rapid distribution of information collected electronically which can lead to the undermining of a client's privacy.

In addition, contact with clients on social media offers the potential for confusion about the nature of the professional/client relationship. For example, if the professional accepts a "friend" request, a great deal of personal information can be exchanged and if the professional does not accept the friend request, this may be experienced as rejection by the client. Social media facilitates contact 24 hours a day which may further complicate the placement of boundaries within the relationship. Social media greatly simplifies the process of sharing information where every exchange can be forwarded to other undefined people. With all electronic communications a screenshot can be used to share information across media, for example, a social media exchange can be screenshot and forwarded by text message to a person outside of the social media network. Boddy and Dominelli (2017) highlight how private spaces on social media can become public as technologically savvy individuals can subvert the high privacy settings put in place by a user. They also point out how public and private boundaries can be blurred as the standards expected by one person giving information may not be shared by the person receiving the information, for example, that the information is private or should only be shared with trusted individuals. In summary, there are few hard and fast rules to guide social workers dealing with the ethical dilemmas presented by social media use in their practice.

\section{Methodology}

The findings reported here represent a subset of findings from the second phase of a small scale qualitative study with newly graduated social workers and teachers regarding their attitudes toward the use of electronic communications in professional practice. Two focus group interviews were utilized as the initial means of data collection and supplemented by a third focus group in order to ensure saturation of key themes. Ethical approval was granted to recruit a purposive sample of participants but recruitment was slow mainly because new graduates have proven a difficult to reach population and we are particularly interested in interviewing graduates within the first 2 years after graduation which means that the 
timeframe for recruitment and interview is relatively limited. Despite the challenges of recruitment, the study sample of 10 participants across the focus groups has included participants from different universities in Ireland, most of whom had commenced employment in social work by the time of interview. There was an almost even gender balance but the ages ranged from early 20 s to late $40 \mathrm{~s}$. Therefore, the findings reported here are not generalizable but, nonetheless, they illuminate a range of attitudes from a cohort of new social workers in the Irish context. Each focus group met once and agreed its own ground rules for discussion. A semi-structured interview was used to ensure coverage of key points and the focus group interviews proved to be very lively and interactive fora with a lot of interaction among participants. As the research was exploratory in nature, and following the approach by Breyette and Hill (2015), we adopted a definition of electronic communication including text and e-mail use as well as social media and websites whose primary function is social networking. In this article, we focus on reporting findings specifically related to the use of social media. The semi-structured interview asked participants to discuss the times when use of social media is helpful and acceptable and to contrast this with types of interaction which they would view as unacceptable in the professional context. As the next section on findings will reveal, in the focus group interviews, opinions were expressed regarding forms of digital contact or surveillance which participants had witnessed in their work. There was considerable debate among participants regarding the appropriateness of some of that contact and an honest sharing of views about judging appropriateness based on the context of the practice.

\section{Findings}

\section{Social presence}

The findings from this study provide an insight into the calculations being made by new social workers about how to handle information from social media in their practice. Social workers are using social media for "light" forms of communication with clients and each other, with due cognizance of the need to pay attention to data security:

We do have a group Whatsapp between the team but we don't discuss clients but we do discuss our whereabouts like 'I'm free if you need me to cover.'

The participants recognize the potential for social media to access hard to reach populations as well as its potential to offer a means of engagement with some clients in the style that the client prefers and is most comfortable with (such as sending text reminders of appointments). However, they 
are uncomfortable with the use of social media for substantial relationship work:

A lot of clients only have text or access to Wi-Fi, they don't have calls so the only way they'd get in contact with you is through text message or social media. Others, teenage kids, might not want to vocalise what they want to say on the phone but if it gets anyway deep, we'd have to follow up with a phone call or a house call to make sure that things are ok.

\section{Surveillance}

The social workers shared a number of examples of how social media is facilitating uncontrolled and, in their view, inappropriate sharing of information among undefined people. The potential of social media for surveillance is being realized and is multi-directional; this includes social workers surveilling clients, clients surveilling family members, and clients surveilling social workers.

\section{Social workers surveilling clients}

Searching for clients on social media raised a considerable dilemma for the social workers in this study. They believed that conducting a social media search on a client crosses an ethical boundary for the professional. Even though a client's social media information may be "public," they perceived that the account itself is part of a client's private life and, therefore, is not something they should engage with in the absence of client consent. It could also generate the possibility of opening up an electronic social connection back to them as a professional:

No way [would I conduct a search for a client on social media]! Because I'd be afraid it'd end up coming back on me and they'd find my Facebook page and then find my family members and start linking stuff. No. I just think it's completely out of our boundaries. In college, I heard people did look up clients on Facebook but I'm against it.

However, it was the view of many participants that investigating clients' private lives is sometimes necessary in social work where risk is deemed to be high and, thus, there are occasions when a social media search is necessary and acceptable, notably in child protection work:

I see the ethical boundary and I know I have crossed it those number of times but you're looking at the safety of children and what they're being exposed to; Is mam posting up pictures of her taking drugs or drinking or is the children in the background? There's always that bit of worry because we have a responsibility to these children but also to protect the ethical boundaries too.

Looking at the client's social media uploads was also seen to be acceptable in a very specific and risky situation for a social worker safeguarding a vulnerable adult: 
[Looking at clients on social media is] over the boundary but, I've a client ... she posts pictures of herself, scantily clad with her name, address and phone number. So it's a safeguarding issue. In order to build a case for her, we had to prove to them, this is what she's doing. So we had to go and have a look ... we were making a decision about the court case, how to represent this girl, to prove to them.

How to use the information obtained during a social media search creates a challenge for the professional/client relationship:

I wouldn't ring the parent and say "well, I'm after seeing you [on Facebook]" but it would give me an area to question a little bit more, push a little bit more. So if a parent says "no I wasn't in the park drinking all day Saturday" I would keep on at it, pushing it, "well where were you," "where were the kids" 'til you get the information.

General and casual sharing of the results of a social media search on clients, however, was seen to be unacceptable:

I do remember in [agency $\mathrm{x}$ ], there was a load of ... social workers, around the computer and they were all laughing at this girl on Facebook saying "look at the state of her" and I was going "no, this isn't right."

It seems that searching for client information on social media involves an ethical calculation for social workers in this study. The belief that such searches are wrong and a violation of a client's private life is weighed against the potential "good" that may accrue from the search especially when protecting children or vulnerable adults.

Interestingly, looking at information on online newspapers or other media sites did not create a similar dilemma as the information is perceived to be public and an acceptable topic for research.

I have Googled stuff ... information that would have been in the newspapers, and on the media about crimes that were committed 20 years ago so I just wanted to learn more about the person, what they did, what might have driven him to do what he did, you know? Well, it was stuff that was out there, the information I would have been getting was ... from newspapers basically so it wasn't anybody's private information or anything like that. It's just stuff that was in the media. I suppose it would've been research.

\section{Client surveillance of family members}

The social workers discussed how clients themselves were using social media for surveillance of family members and using that information to influence decision making by social workers and other professionals. For example, information from social media is being used by clients in court to influence the judge:

I have clients that bring printouts of their Messenger messages and screenshots of other people's Facebook pages to court, to family court, to try to prove a point and they are definitely being taken into consideration a little bit more within the courts 
so that's a huge change. So solicitors are using them to build a file against the other person.

Parents are also using social media to gather information on their children and sharing it with the social worker in an attempt to influence practice:

I have a mother who keeps getting on her son's Facebook account and he keeps on changing the password but she keeps on getting it and she screenshots me conversations he's having with other people-she's taking that private information from a 16 year old and handing it to a social worker without his consent. I know he's still young but the content is just conversations ... not that he'd be exposed to sexual violence or anything like that ... it's more ... anti-social stuff.

This raises complicated issues of consent and places a burden on the social worker about how to handle it as part of the professional relationship with the child:

I have to go and say 'Your mother is after sending this to me' because I had to inform him of where it came from.

\section{Client surveillance of social workers}

The social workers were acutely aware of the potential for surveillance by clients through social media and took steps to protect themselves. They were mindful of the need to keep their social media accounts "private" by blocking wide public access as much as they could and permitting access to a small group of friends and family only. Some were using a different name on their accounts to make surveillance harder:

WhatsApp, I'm on professionally, I would be on Facebook and Instagram but that would be personal and I keep it completely private, I have my name slightly different and all so that clients can't access me. I remember when I was in college on placement, my page wasn't fully private, well it was but you could still probably see some pictures and stuff on the friends you know, clients were coming up so I had to shut that down and change it.

However, maintaining one's privacy requires knowledge about the settings on social media platforms:

I still find my privacy within my friend list. I don't know... Can you change when you were last online in messenger? ... You know, certain people you might not want to speak to or you don't have time for, they can see you're on your Facebook page and then they message.

It is not just their own social media accounts that hold the potential for surveillance. One social worker revealed their vigilance about appearing in clients' photographs which could be posted to social media or forwarded:

We do spend a lot of time out and about with families on access and they'd be taking photographs and we might be in the background ... you have to be very 
aware and keep your face out of those photos, put your hand up or move out of the way.

However, one emerging and controversial avenue for surveillance is the potential for video recording of the social worker during meetings with clients and distribution of the video, and photos on social media. This type of experience was reported by participants during the focus group discussions:

[We've had video] streaming during access, taking photos of us and threatening to put them on social media. There's the [Agency name] Child Robbers page. So we have to be very careful. Any phone use in close proximity, we have to be alert.

The social workers experiencing this type of surveillance had to figure out how to protect themselves. Legally, the recording is permitted so study participants resorted to the premature shutting down of a meeting where it occurred.

\begin{abstract}
... we can't actually stop the client from videoing us, they do have a right to do that and they have a right to publish it online, Facebook, we cannot stop that ... we would try to shut a meeting down where that was the case but there's no legal standing to protect a meeting unless there's confidential information about another person being shared within that meeting. But as professionals providing a government service, no [we can't stop it].
\end{abstract}

\title{
Discussion
}

It is clear that social media, particularly an application like WhatsApp, offer additional communication channels which facilitate increased social presence as described by LaMendola (2010). In this study, it was useful in increasing the social presence between social workers and certain clients such as teenagers and young parents as well as the social presence between geographically dispersed social work team members. However, the social workers in this study were reluctant to use social media directly with clients for anything more than short and superficial communications. Incorporating it into a new social work practice as envisaged by Simpson (2017) is challenging, not just from a skills perspective as outlined by Taylor (2017), but also due to the practice dilemmas it creates, both ethical and legal in nature.

The findings from this study echo the ethical dilemmas highlighted by numerous authors including Breyette and Hill (2015), Gabbard and colleagues (2011), and Mishna and colleagues (2012). The easy access and rapid spread of information both purposively and inadvertently by social media (Judd \& Johnston, 2012) is a fact of life and, thus, a fact of social work. The very objective of social media-the easy exchange of information-can act as an accelerant in social relationships facilitating uncontrolled sharing among undefined persons. Social media facilitates the spread of information, often without consent, which undermines privacy 
and confidentiality. This bears the hallmarks of social surveillance as outlined by Marwick (2012) and in this study, the surveillance was multidirectional including the recording of social workers by clients in the course of their work and having the video disseminated without their consent. In responding to the surveillance by clients, the social workers in this study sought legal guidance and protection navigating within the paradigm of legal rights and regulatory control often espoused in social media use (Bekkers et al., 2013). However, there is scope to consider surveillance actions by clients as a response to power asymmetry in the client/professional relationship and a stimulus perhaps to consider the role of social media in antioppressive practice (Dominelli, 2002), and in providing voice to those whose stories may not otherwise be heard (La Rose, 2012). When social work is framed as a profession of change (Strier \& Bershtling, 2016), resistance can be viewed as an act that counters coercive practices of social control. Resistance in social work does not only arise from the acts of professionals, however, and Ferguson and Lavalette (2006) identify service user resistance as one of four sources of resistance. With this framing, client use of surveillance can be recognized by social workers as an act of resistance with the aim of addressing power asymmetry.

Searching for clients on social media was seen to be unacceptable by the social workers in this study, even when the client's account is "public." The social workers perhaps perceive a "front stage/back stage" distinction (Goffman, 1959) and think that a client is unlikely to imagine his or her social worker as the audience for what they present on social media. An ethical exception, however, may be made when the risk assessment warrants it and when children or vulnerable adults were involved, some social workers said they would search for and use information gleaned from social media.

Social media involves a collapse of social contexts and social roles which complicates the navigation of boundaries (Reamer, 2017). Navigating boundary complexity is part of normal life but particularly problematic for social workers who recognize the power implications of boundaries (Boddy \& Dominelli, 2017). This is problematic for professionals, particularly those with a statutory remit and in common with Breyette and Hill (2015) this study identified a number of novel and emergent challenges for child protection and welfare social workers in the use of social media.

In the face of these practice realities, social workers undoubtedly need practical support and guidance from employers, regulatory bodies, professional bodies, and educators. As discussed by others (Breyette \& Hill, 2015), standards, codes and guidelines are undoubtedly important to help social workers navigate these practice realities. However, given the rapid change in technology and its use, highly directive guidelines may be out of 
date by the time they are disseminated. Education with reference to general principles such as privacy and consent may prove to be more useful to social workers and help them to make the complex calculations about social media use which are often affected by context (Barsky, 2017).

Skill and competence development (Taylor, 2017) is also key. To protect themselves and clients on social media, there is a need for basic training for social workers, for example, on how to manage privacy settings across a range of social media platforms. However, because of the power dynamics involved in social surveillance generally (Marwick, 2012), it seems appropriate to consider the extent to which the use of social media moves the debate regarding care versus control to a new dimension and what types of knowledge social workers need to engage in critical self-reflection and antioppressive practice in this domain.

\section{Conclusion}

Social media use is ubiquitous in life and, thus, is a practice reality for social workers. Technology morphs constantly and social workers must be alert and responsive to the associated threats and opportunities from its use. Given the speed of change, hard and fast rules can be hard to come by as human service organizations and regulatory bodies struggle to issue standards, protocols, and codes at pace with practice realities. In an era where social media can facilitate multi-directional surveillance, social workers need practical support, not least from their employers who should be able to provide legal guidance and competence development to inform and protect their staff. Social workers also need support from social work educators and professional bodies who can provide principle-based education and guidance on topics such as privacy, consent and boundaries to help them navigate the ethical dilemmas associated with social media use in practice. However, surveillance through social media has the potential to disrupt the power dynamics in the client/social worker relationship. It can be seen as an act of resistance in the face of coercive practices of social control. Thus it seems appropriate for social workers, their employers, educators, and professional bodies to zoom out and consider the use of social media by professionals, and clients, through the lens of critical self-reflection and anti-oppressive practice.

\section{ORCID}

Julie Byrne (D) http://orcid.org/0000-0002-5913-1158

Gloria Kirwan (D) http://orcid.org/0000-0002-5663-1325

Conor Mc Guckin (D) http://orcid.org/0000-0001-5848-2709 


\section{References}

Ballantyne, N., \& LaMendola, W. (2010). Human Services in the Network Society: Introduction to the Special Issue. Journal of Technology in Human Services, 28(1-2), 1-6.

Boddy, J., \& Dominelli, L. (2017). Social media and social work: The challenge of a new ethical space. Australian Social Work, 70(2), 172-184.

Barsky, A. E. (2017). Social work practice and technology: Ethical issues and policy responses. Journal of Technology in Human Services, 35(1), 8-19.

Bekkers, V. J. J. M., Edwards, A. R., \& de Kool, D. (2013). Social media monitoring: Responsive governance in the shadow of surveillance. Government Information Quarterly, 30(4), 335-342.

Breyette, S. K., \& Hill, K. (2015). The impact of electronic communication and social media on child welfare practice. Journal of Technology in Human Services, 33(4), 283-303.

CORU. (2011). Code of professional conduct and ethics for social workers. Retrieved from: http://coru.ie/uploads/documents/typeset_Social_Worker_Code_Feb_2010.pdf

CORU (2019). Social workers registration board code of professional conduct and ethics. Retrieved from http://coru.ie/uploads/documents/2019_03_06_SWRB_Code_for_Website.pdf

Dominelli, L. (2002). Anti-oppressive social work theory and practice. London: Palgrave Macmillan.

Gabbard, G. O., Kassaw, K. A., \& Perez-Garcia, G. (2011). Professional boundaries in the era of the internet. Academic Psychiatry, 35(3), 168-174.

Goffman, E. (1959). The presentation of self in everyday life. Garden City, NY: Doubleday.

Glastonbury, B., \& LaMendola, W. (1992). The integrity of intelligence: A bill of rights for the information age. London: The Macmillan Press.

Ferguson, I., \& Lavalette, M. (2006). Globalization and global justice: Towards a social work of resistance. International Social Work, 49(3), 309-318.

Fook, J. (2016). Social work: A critical approach to practice. London: Sage Publications.

Heron, B. (2005). Self-reflection in critical social work practice: Subjectivity and the possibilities of resistance. Reflective Practice, 6(3), 341-351.

Jewkes, Y., \& Andrews, C. (2005). Policing the filth: The problems of investigating online child pornography in England and Wales. Policing and Society, 15(1), 42-62.

Judd, R. G., \& Johnston, L. B. (2012). Ethical consequences of using social network sites for students in professional social work programs. Journal of Social Work Values and Ethics, 9(1), 5-10.

Kirwan, G. (2012). Social media, e-professionalism and netiquette in social work. Irish Social Worker, Autumn, 9-12.

Kirwan, G., \& Mc Guckin, C. (2014). Digital natives or digitally naïve? E-professionalism and ethical dilemmas among newly graduated teachers and social workers in Ireland. Journal of Technology in Human Services, 32(1-2), 119-132.

Kondrat, M. E. (1999). Who is the self in self-aware: Professional self-awareness from a critical theory perspective. Social Service Review, 73(4), 451-477.

LaMendola, W. (1988). Networks and electronic communication. In B. Glastonbury, W. LaMendola, \& S. Toole (Eds.), Information technology and the human services. London: John Wiley \& Sons.

LaMendola, W. (2010). Social work and social presence in an online world. Journal of Technology in Human Services, 28(1-2), 108-119.

La Rose, T. (2012). Digital media stories through multimodal analysis: A case study of Erahoneybee's song about a child welfare agency. Journal of Technology in Human Services, 30(3-4), 200-311. 
Marwick, A. E. (2012). The public domain: Surveillance in everyday life. Surveillance \& Society, 9(4), 378-393.

Mishna, F., Bogo, M., Root, J., Sawyer, J. L., \& Khoury-Kassabri, M. (2012). 'It just crept in': The digital age and implications for social work practice. Clinical Social Work Journal, 40(3), 277-286.

NASW, ASWB, CSWE \& CSWA. (2017). Standards for Technology in Social Work Practice. Retrieved from http://www.socialworkers.org/includes/newIncludes/homepage/ PRA-BRO-33617.TechStandards_FINAL_POSTING.pdf.

Nellis, M. (2010). Eternal vigilance Inc.: The satellite tracking of offenders in "real time". Journal of Technology in Human Services, 28(1-2), 23-43.

Parton, N. (2006). Changes in the form of knowledge in social work: From the 'social' to the 'Informational'? British Journal of Social Work, 38(2), 253-269.

Patton, D. U., Eschmann, R. D., Elsaesser, C., \& Bocanegra, E. (2016). Sticks, stones and Facebook accounts: What violence outreach workers know about social media and urban based gang violence in Chicago. Computers in Human Behavior, 65, 591-600.

Reamer, F. G. (2017). Evolving ethical standards in the digital age. Australian Social Work, $70(2), 148-159$.

Simpson, J. E. (2017). Staying in touch in the digital era: New social work practice. Journal of Technology in Human Services, 35(1), 86-98.

Strier, A., \& Bershtling, O. (2016). Professional resistance in social work: Counterpractice assemblages. Social Work, 61(2), 111-118.

Taylor, A. (2017). Social work and digitalisation: Bridging the knowledge gap. Social Work Education, 36(8), 869-879.

Ventola, C. L. (2014). Social media and health care professionals: Benefits, risks, and best practices. A Peer-Reviewed Journal for Managed Care and Hospital Formulary Management, 39(7), 491-499. Retrieved from https://www.ncbi.nlm.nih.gov/pmc/articles/PMC4103576/

Yao, M. Z., Rice, R. E., \& Wallis, K. (2007). Predicting user concerns about online privacy. Journal of the American Society for Information Science and Technology, 58(5), 710-722.

Yonkova, N., \& Kirwan, G. (2018). Human trafficking and gender-based violence: From life and limb to hearts and minds. In S. Holt, C. Ǿverlien, \& J. Devaney (Eds.), Responding to domestic violence: emerging challenges for policy, practice and research in Europe. London: Jessica Kingsley Publishers. 